\title{
Feasibility of a single endoscopic plication procedure for the treatment of gastro- esophageal reflux disease and obesity
}

Gastroesophageal reflux disease (GERD) and obesity are common disorders in the developed world, often coinciding in the same patients [1]. Obesity exacerbates GERD and reduces the efficacy of anti-reflux surgery [2]. This creates management challenges for overlapping GERD and obesity, which compels the development of safe, effective, and durable therapies for patients with these conditions. The Incisionless Operating Platform (USGI Medical, San Clemente, California, USA) is a handheld endoscopic tool that acquires full-thickness gastric or gastroesophageal tissue using $3.3-\mathrm{cm}$ jaws. The tissue is then pierced with a catheter needle to allow for the deployment of paired suture anchors, thereby creating a $6.6-\mathrm{cm}$ full-thickness plication ( $\triangleright$ Video 1 ). The Incisionless Operating Platform may be operated in both the forward-facing and retroflexed orientation. This unique feature permits the endoscopic creation of plications that both facilitate weight loss (such as those used in the Primary Obesity Surgery Endoluminal gastric remodeling procedure), as well as plications at the gastroesophageal junction that may serve as a barrier against pathologic reflux (such as those used in transoral incisionless fundoplication) $[3,4]$. The Incisionless Operating Platform consequently provides the theoretical opportunity to co-treat obesity and GERD in the same patient during a single procedure ( Fig.1). In this video, we describe the use of the platform to create gastric plications in the pattern of the Primary Obesity Surgery Endoluminal 2 procedure, which tubularizes the stomach along the greater curvature and shortens its aperture to facilitate weight loss in adults with obesity. We then describe the use of the Incisionless Operating Platform to create gastric and gastroesophageal plications to serve as a barrier against gastroesophageal reflux in a

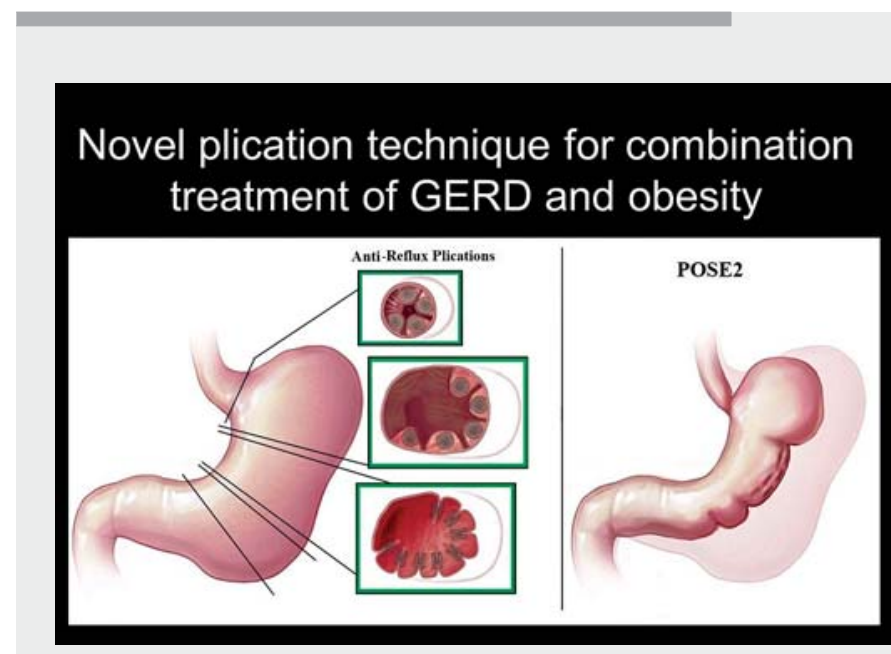

Video 1 Single endoscopic plication procedure for treatment of gastroesophageal reflux disease and obesity. Source for graphical illustration: Mayo Clinic. Source for IOP: USGI Medical.

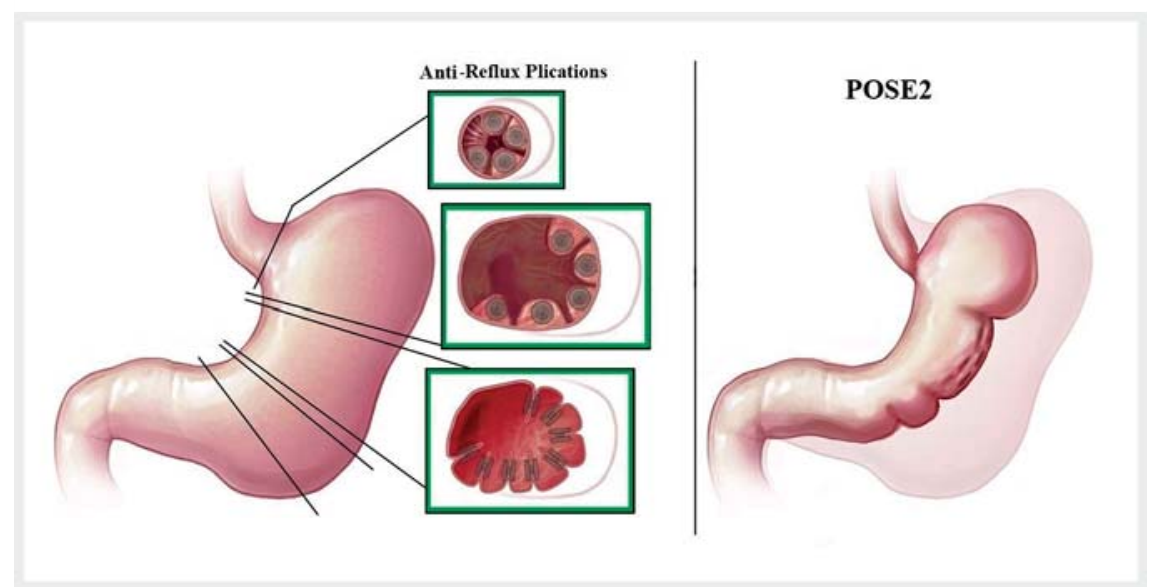

- Fig. 1 Novel plication technique for combination treatment of gastroesophageal reflux disease and obesity. Source: Mayo Clinic.

large canine model. We conclude with the combination plication procedure in an ex-vivo porcine stomach, providing the conceptual framework for examining the combination procedure in humans.

Endoscopy_UCTN_Code_TTT_1AO_2A]
Competing interests

KST: USGI Medical (consultant), Endogastric Solutions (consultant, speaker); GLN: Apollo Endosurgery (consultant), USGI MedicaL (consultant), Nitinotes (consultant); RT: USGI Medical (consultant); BKA: Boston Scientific (consultant), USGI (consultant, grant/ research support), DyaMx (consultant), Metamodix (consultant), Olympus (speaker), 
Medtronic (speaker, grant/research support), Johnson and Johnson (speaker), Endogastric solutions (speaker), Apollo Endosurgery (grant/research support), Cairn Diagnostics (grant/research support), Aspire (grant/research support), Spatz (grant/research support).

The authors

Daniel B. Maselli ${ }^{1}$, Rami Abusaleh ${ }^{1}$, Karim S. Trad $^{2}$, Gontrand Lopez-Nava ${ }^{3}$, Román Turró ${ }^{4}$, Barham K. Abu Dayyeh ${ }^{1}$

1 Division of Gastroenterology and Hepatology, Mayo Clinic, Rochester, Minnesota, USA

2 The George Washington University School of Medicine and Health Sciences, Washington, DC, USA

3 Bariatric Endoscopy Unit, Madrid Sanchinarro University Hospital, Madrid, Spain

4 Unidad de Endoscopia, Centro Médico Teknon, Barcelona, Spain
Corresponding author

\section{Barham K. Abu Dayyeh, MD}

Division of Gastroenterology and Hepatology, Mayo Clinic, 200 First Street SW, Rochester, MN 55905, USA Fax: +1-507-284-0538

AbuDayyeh.Barham@mayo.edu

\section{References}

[1] Rubenstein JH, Chen JW. Epidemiology of gastroesophageal reflux disease. Gastroenterol Clin North Am 2014; 43: 1-14

[2] Khan A, Kim A, Sanossian C et al. Impact of obesity treatment on gastroesophageal reflux disease. World J Gastroenterol 2016; 22: 1627-1638

[3] López-Nava G, Bautista-Castaño I, Jimenez A et al. The Primary Obesity Surgery Endolumenal (POSE) procedure: one-year patient weight loss and safety outcomes. Surg Obes Relat Dis 2015; 11: 861-865

[4] Sami Trad K. Transoral incisionless fundoplication: current status. Curr Opin Gastroenterol 2016; 32: 338-343
Bibliography

Endoscopy 2022; 54: E203-E204

DOI 10.1055/a-1481-7844

ISSN 0013-726X

published online 12.5 .2021

(c) 2021. Thieme. All rights reserved.

Georg Thieme Verlag KG, Rüdigerstraße 14, 70469 Stuttgart, Germany

\section{ENDOSCOPY E-VIDEOS}

https://eref.thieme.de/e-videos

回序回 Endoscopy E-Videos is an open access online section, 回些: reporting on interesting cases and new techniques in gastroenterological endoscopy. All papers include a high quality video and all contributions are freely accessible online. Processing charges apply (currently EUR 375), discounts and wavers acc. to HINARI are available.

This section has its own submission website at https://mc.manuscriptcentral.com/e-videos 